\title{
The Eyes Have It! Our Third Official Language: New Zealand Sign Language
}

\author{
RACHEL LOCKER MCKEE \\ Victoria University of Wellington
}

New Zealand gained a third official (second statutory) language with the passage of the New Zealand Sign Language (NZSL) Act in April 2006. This landmark was heralded with elation by the Deaf community who have struggled for the right to exercise citizenship through a language that is fully accessible via the eyes. It is Deaf people's visual orientation to the world that shapes their preference for sign language, structures their cultural experience and sets them apart as a community from the hearing majority. ${ }^{1}$

The achievement of official language status for NZSL is apparently unique among signed languages of the world; many national and state governments have accorded various forms of recognition to a signed language, but no others have 'official language' status. ${ }^{2}$ Why has the New Zealand government recognized NZSL as a third official language? Language policy makes and promotes certain choices about language use, against a backdrop of sociohistorical facts; such decisions thus have social meaning. ${ }^{3}$ Does the almost unanimous support for this Act signal heightened political sensitivity to issues of diversity, inclusiveness and equity? Or did the negligible material implications of the Act engender its passage as a compensatory gesture towards a disadvantaged community? Deaf New Zealanders have undoubtedly benefited from the socio-political climate generated by the Maori Language Act 1987 and government commitment to the participatory rights of people with disabilities, as formalized in the New Zealand Disability Strategy.

This article critically examines the background, scope and likely impacts of the NZSL Act 2006, with comparative reference to the Maori Language Act (MLA) and cases of sign language recognition overseas. Consideration of the motives and process surrounding the NZSL Act shows that it is predicated on a hybrid ideology which draws upon principles of human rights, disability rights and minority linguistic rights, to re-position the status of NZSL users symbolically and promote their right to societal participation. 


\section{The Status of Sign Languages and Their Users}

Because the sign languages of Deaf people have been historically denigrated as less than fully language-like and even conducive to social deprivation, discussion of their political status necessarily starts by confirming that they possess the characteristics of natural human languages. ${ }^{4}$ A large body of linguistic research has shown that geographically distinct sign languages are internally structured, rule-governed systems capable of expressing abstract thought, which grow and change through natural usage in Deaf communities over historical time, like spoken languages. ${ }^{5}$ The natural sign languages that evolve within Deaf communities are often incorrectly conflated with contrived 'sign systems' that manually represent spoken language, used for the pedagogical purpose of supporting Deaf children's acquisition of speech and literacy. Sign systems (or manual codes) have been found to be both functionally and socio-linguistically problematic, and are currently waning in acceptability and usage in Deaf education. ${ }^{6}$

Language planning has been described as 'deliberate decision making in response to language problems'? Internationally and historically, Deaf people have been on the receiving end of language planning in education systems controlled by non-Deaf authorities. The enduring tension here is between the use of natural sign language as a comprehensible vehicle of learning and an oralist approach (teaching exclusively through speech) that aims for linguistic and social normalization. The balance of power tends strongly towards the latter. ${ }^{8}$

Legal recognition of sign languages is therefore high on the Deaf political agenda; the World Federation of the Deaf policy document, 'Call for the Recognition of Sign Languages', invokes minority language rights in seeking national recognition of the 'indigenous languages' of Deaf communities. ${ }^{9}$ Since the 1980 s, critical deconstruction of the relationship between the suppression of sign languages and the pejorative social position of Deaf people $\mathrm{e}^{10}$ has underpinned successful Deaf activism. Many countries have recognized the rights of their sign language users through a variety of legislative and policy measures. In some cases, recognition simply acknowledges the linguistic status of a sign language and its community of users, while in others, the instrumental right to use sign language in particular domains is specified - typically in educational, legal and medical arenas. ${ }^{11}$ A report on the status of sign languages in Europe, for example, comments as follows:

The question for governments is not anymore whether to recognise sign languages or not, but when and how to recognise sign languages. Finland and Portugal have recognised sign language [users] by amending 
their constitutions and enacting corresponding legalisation. The Frenchspeaking Community of Belgium, the Czech Republic, Denmark, Germany, Greece, Ireland, Italy, Lithuania, Norway, Poland, the Slovak Republic, Slovenia, Sweden, Switzerland and the United Kingdom have recognised sign language in acts and laws, often in relation to education or the profession of sign language interpreting. ${ }^{12}$

While the protection of sign language is advocated in tandem with recognition of Deaf culture, ${ }^{13}$ the fundamental motive for recognizing sign languages goes deeper than valorization of cultural-linguistic identity. More essentially, access to sign language - especially for those born Deaf - arguably fulfils the need and the right to communication itself, and an accessible route to the mental, social and cultural life that is assumed to be a given of human existence and prerequisite to being a productive citizen. ${ }^{14}$ For Deaf people who use a visual language, achieving linguistic rights is inseparable from materializing basic human rights which depend on being able to communicate meaningfully with others - in the family, at school and in adult society.

Progressing these linguistic human rights is complicated by the challenge of establishing 'mother tongue' or native language status for sign language users. ${ }^{15}$ Sign language communities are constituted rather uniquely, in that 95\% of Deaf people are raised in non-Deaf families and are thus not socialized 'natively' into a signing Deaf community, but typically acquire sign language and Deaf culture in a community of peers at school or later. ${ }^{16}$ Contemporary challenges to the survival of sign language communities in western societies include mainstreaming as a mode of schooling (which isolates Deaf children from other sign language users), the popularity of cochlear implants for Deaf infants and advances in genetic bio-technology aimed at reducing hereditary deafness. ${ }^{17}$

The choice of using spoken or sign language with young Deaf children as a means of communication at home and at school is highly contested, and is a decision that is generally made by parents whose only point of reference for language and identity is a speaking-hearing community. The pervasive belief that education through the dominant language of society (spoken English) is the key to academic, social and economic integration inherently privileges a monolingual approach to schooling. But, regardless of communication mode or school setting favoured, the problem remains that 'the complete linguistic socialization of Deaf children into the hearing speech community is exceedingly difficult to accomplish since these children are different from mainstream members in such a crucial way'. ${ }^{18}$ Accordingly, Deaf people do not advocate access to sign language just in 
terms of cultural identity politics, but as a communicative necessity to access the world around them.

The experience of signing communities is closely bound to the history of Deaf education. In most countries, special residential schools for the Deaf have inadvertently created a critical mass of Deaf peers that allows for the genesis and passing on of sign language between generations. In these peer networks, the small number of Deaf children with Deaf parents (about 5\% of the Deaf population) who are 'native' signers are key agents in the intergenerational dissemination of language and cultural strategies for living in both Deaf and non-Deaf worlds. ${ }^{19}$ Whilst the dormitories and playgrounds of Deaf schools have been habitats for the survival of sign languages and Deaf communities, the institution of Deaf education has historically been the locus of repressive language policies that have ensured the subordinate status of sign languages and silenced Deaf people's voice. ${ }^{20}$ The experience of the NZSL community echoes that of Deaf people the world over whose visual language has been stigmatized, leading to the negative social outcomes that are familiar to colonized minorities. ${ }^{21}$

\section{Origins of NZSL}

Though historically related to British Sign Language, ${ }^{22}$ NZSL has evolved locally over approximately a century, following the establishment of the Sumner School for the Deaf and Dumb in 1880 and subsequent schools (and Deaf communities) in Auckland and Feilding. The approved teaching method until 1979 was oralism, but NZSL existed underground in the social life of Deaf children. ${ }^{23}$

The signing used covertly by Deaf people over many generations has been formally named as NZSL only since about 1985 . Following the pioneering linguistic study of American Sign Language by William Stokoe in the 1960s, the signing of New Zealand Deaf people was first studied empirically by Peter Ballingal, a teacher of the Deaf who analysed the playground language of his pupils. ${ }^{24}$ His conclusion that their communication had the hallmarks of an internally-structured language system was dismissed by the establishment at the time, but opened a door to consideration of the Deaf community's signing as something more than random gestures and pantomime.

In response to the persistently low academic achievement of Deaf children, a sign system known as Australasian Signed English or Total Communication was introduced into New Zealand schools from 1979.25 This was used until awareness of the Deaf community's natural sign language led to policy change in the early 1990s. Pivotal to this shift was Collins-Ahlgren's research on the grammar and lexicon in use by the adult Deaf community, ${ }^{26}$ which established the term 'New Zealand Sign Language'. This study validated 
the status of NZSL as a language and was a powerful factor in altering the consciousness of the Deaf community - enabling them to articulate their identity as a language-based community and culture. The first training course for professional sign language interpreters in $1985,{ }^{27}$ which also documented a large lexicon of vernacular signs, ${ }^{28}$ was an important practical affirmation to both Deaf and hearing people that NZSL was an appropriate vehicle for conducting everyday transactions in the public domain, contrary to what they had been indoctrinated to believe. ${ }^{29}$ As sign language research and 'Deaf Pride' gained traction during the late 1980s and early 1990s, NZSL gained greater acceptance, and Deaf people's demand for access to civic life via interpreting services grew apace. ${ }^{30}$ Deaf NZSL users have been estimated to number between $4,500-7,700$, depending on the basis for calculation. ${ }^{31}$

\section{History of the NZSL Act}

Roots of the NZSL Act can be traced to the 1996 Labour Party manifesto, which promised a new ministerial portfolio for disability. ${ }^{32}$ This reflected an ideological acceptance of a social model of disability which asserts that disability is constructed by societal barriers, rather than being inherent in individuals' physical impairments, and society therefore has an obligation to address those barriers at a structural level. By 1999, lobbying by the Deaf Association with support from the Disabled Persons Assembly about Deaf people's disadvantage in the education and justice systems in particular led to a Labour Party commitment to recognize NZSL legally. ${ }^{33}$ Subsequently, the New Zealand Public Health and Disability Act of 2000 required the formulation of the New Zealand Disability Strategy, ${ }^{34}$ with the objectives of equalising participation and outcomes for people with disabilities in education, employment and economic development. For the Deaf community, communication access was central to meeting these objectives.

The Office for Disability Issues (ODI) was established in 2002 to develop and monitor disability-related policy across government departments, in accordance with Disability Strategy objectives. In 2003, Victoria Manning, a Deaf person employed as a policy analyst at the ODI, led a nation-wide consultation with the Deaf community as a first step towards developing a NZSL Bill that would fulfil Labour's manifesto promise and also address the objectives of the Disability Strategy. ${ }^{35}$ Three themes emerged from the community consultation:

(i) Low awareness of Deaf people within the state sector and wider society;

(ii) Poor access to government services, and large discrepancies between the ways in which Deaf people and government agencies perceive the accessibility of government services for Deaf people; 
(iii) Inadequate funding and development of sign language interpreter services. ${ }^{36}$

This consultation gave direction for a draft Bill to address the Deaf community's dual aspiration for official recognition of their language and for better access to public services and information through NZSL.

The ensuing consultation with 27 government agencies on a draft proposal, however, revealed that 'government agencies could not implement a Bill that moved very far from the status quo, because of resource limitations', and highlighted 'difficulties in specifying enforceable rights or obligations with enough clarity to apply these in the myriad of circumstances in which they operated'. ${ }^{37}$ In order to be both administratively and politically acceptable, the final form of the Bill specified enforceable rights only in legal proceedings and declared official recognition, without imposing additional costs.

The Hon. Ruth Dyson, Minister for Disability Issues, introduced the NZSL Bill to Parliament in April 2004. A large audience of Deaf people in Parliament and around the country watched this first reading of the Bill which was simultaneously interpreted into NZSL and broadcast live on the internet. ${ }^{38}$ The Justice and Electoral Select Committee considered public submissions later in 2004, a process which raised consciousness on both sides: instructions for submitters were made available in NZSL webclips by the ODI, and the committee received submissions in writing and in NZSL on videotape, as English is not the first language of many NZSL users. 'Hearing' the presentations of Deaf submitters required arranging interpreters, live captioning and video-conferencing to make proceedings accessible to all participants. Members of the Select Committee commented during subsequent parliamentary debates on the impact of this on their understanding of what it means to facilitate 'access' and 'inclusion' for sign language users. For the Deaf community, this was the first time that they had been directly involved in - and enabled to access - the legislative process; it was an empowering experience to articulate their experiences and aspirations directly to the highest level of state authority, via the Select Committee, after lifetimes of feeling disenfranchized by communication barriers.

My analysis of written and oral submissions on the Bill (which I attended in Wellington, 9 February 2005) shows these to express four main motives:

1. restoring cultural and psychological esteem to NZSL users through official recognition - reversing the collective harm suffered through stigmatization of sign language;

2. securing and implementing the right to access public services and information through NZSL (via interpreting services and/or translated 
material), and also improving communication access in areas that fall outside state-funded services (e.g. broadcasting, employment, etc.);

3. making compulsory education available through NZSL, as of right, for Deaf children;

4. material support for the maintenance and promotion of NZSL, both within Deaf community domains and by encouraging others in the wider community to learn and use NZSL - effectively increasing Deaf people's inclusion in society. ${ }^{39}$

In its report to Parliament, the Select Committee acknowledged that it could not address all of these concerns within its recommended amendments to the Bill, which ultimately remained close to its draft form. The Select Committee's recommendations were presumably constrained by the knowledge that adding resource implications to the legislation would hinder its passage and capacity to be implemented in the current environment.

One objection to the Bill was raised in submissions, and one by the ACT Party during the three debates in the House. Objectors suggested a risk of creating inequitable privilege by according special rights to one language group, and potentially opening the floodgates to similar demands by immigrant language communities. An analysis of the consistency of the NZSL Bill with the New Zealand Bill of Rights establishes that it does not impinge on the rights or freedoms conferred by any previous legislation, nor privilege NZSL users over any others. ${ }^{40}$ The Act also specifies that official recognition is premised on NZSL having no other home country - in effect, being indigenous to New Zealand.

A second counter-argument was that government support would be better directed to more medical intervention and technological assistance to prevent and remediate the limitations created by hearing impairment. This argument is considered irrelevant by the Deaf community who seek validation not rehabilitation of their cultural and linguistic identity, a perspective that was clearly understood by the majority of MPs responding to the Bill. The third and most plausible objection was the lack of an associated budget and the contingent risk of the law being merely symbolic - raising aspirations but not materially changing the status quo. This concern was also expressed in submissions that supported the Bill. The Select Committee response was to indicate the role of policy in putting the principles of the Act into practice, and to recommend a review of its effect in three years' time.

The NZSL Act was passed by 119-2 at its third reading on 6 April 2006, to a storm of hand-waving, foot-stomping 'Deaf applause' from the public gallery. Minister Dyson commented at a celebratory function afterwards 
on the powerful wave of emotion felt by all present in the House at that moment.

\section{Provisions of the NZSL Act}

The NZSL Act (2006) has three major provisions. The first declares official language status for NZSL, acknowledging it to be the first or preferred language of members of the Deaf community, and one which exists uniquely in New Zealand. Secondly, it guarantees the right to use NZSL in legal proceedings where it is a person's first or preferred language, with the provision of competent interpreters. Thirdly, it sets out principles to guide government departments in the use of NZSL to promote and deliver their services ('so far as reasonably practicable'). The Act enables the Minister for Disability Issues to report on the implementation of these principles under the reporting mechanism for the New Zealand Public Health and Disability Act 2000, which measures the progress of government departments towards the goals of the New Zealand Disability Strategy. The Act also specifies that its effects will be reviewed in three years' time.

The Bill primarily addresses the uncertain legal status of NZSL. ${ }^{41}$ The need to clarify the status of NZSL and its users arises from the fact that existing legislation does not explicitly afford protection from discrimination on the grounds of language; analyses of the applicability of the New Zealand Bill of Rights Act 1990 and the Human Rights Act 1993 to language rights conclude that language is subsumed as an aspect of race, ethnicity or national origin, while the ground of disability offers only indirect protection of the right to communicate in sign language. ${ }^{42}$ As Deaf people do not squarely fit the definition of an ethnic minority, yet have suffered inequities as a result of linguistic discrimination, the NZSL Bill aimed to confer on NZSL a status equal to an indigenous spoken language, and further, to strengthen Deaf people's right to use that language in accessing public services. Although the Bill notes that currently, '(p)rovisions for the use of NZSL interpreters are inadequate', no new rights or obligations have actually been created in this respect; the right of individuals who do not understand English or Maori to interpretation in legal proceedings is already established through case law and statutes, ${ }^{43}$ and in customary practice. The NZSL Act alters the status quo only by identifying NZSL users as a class of people entitled to interpreter provision, alongside Maori speakers, and by requiring that interpreters be 'competent' (a term yet to be operationalized).

\section{Comparison with the Maori Language Act}

Like the Maori Language Act, which 'restores or compensates for losses', ${ }^{44}$ the NZSL Act aims to remedy the fact that 'Deaf New Zealanders have not 
been afforded the same right to their language as other New Zealanders' and have suffered serious disadvantage as a result. ${ }^{45}$ The provisions and wording of the NZSL Act draw closely upon those of the Maori Language Act, which in turn cites the Welsh Language Act 1967 (UK) and Bord $\mathrm{Na}$ Gaeilge Act 1978 (Eire) as precedents. Provisions of the two Acts are compared in Table 1, appended.

The most significant difference between the two Acts, as shown in Table 1, is the absence in the NZSL Act of the powers assigned to the Maori Language Commission to foster and regulate community and official uses of the language. Instead, the NZSL Act enjoins government agencies to observe the principles of the Act in the delivery of their services. Although mentioned in the regulations (s13), the NZSL Act also gives less direction regarding the administration of competency standards for legal interpreters. Finally, the NZSL Act lacks the provision ${ }^{46}$ to appropriate government funds for implementation. The Select Committee rationalized this rather significant point as follows: 'Several submitters commented on the need for ongoing and strategic funding to ensure that New Zealand Sign Language can be effectively maintained and promoted. However we considered that there was a need to monitor and report on the legislation before making any recommendations about funding. ${ }^{47}$ A cynic might predict that the lack of funding might guarantee little activity to monitor and report upon at the time of review.

\section{Symbolic and Instrumental Impacts of the Act}

Models of language policy and planning identify dimensions of language planning, which can be summarized broadly into three key areas of activity: status planning (selecting and implementing the roles or domains for use of a language), corpus planning (codification and documentation that may assist in extending the use of a language for new functions and in new contexts), and acquisition planning (supporting conditions for disseminating and maintaining the vitality of a language). ${ }^{48}$ Theorists generally agree that the position of minority languages is most effectively strengthened when these areas of activity are jointly planned. ${ }^{49}$ The NZSL Act is one element of a patchwork of planning efforts that ultimately affects the status and opportunities of the Deaf community, which have emerged piecemeal rather than strategically until now.

Making NZSL an official language radically elevates its status to a par with English and Maori (in principle, at least), and formalizes the Deaf community's desire to maintain a distinct cultural-linguistic identity - a fundamental minority linguistic right. ${ }^{50}$ The most immediately-felt effect of the Act by the NZSL community may well be the symbolic, statutory 
acknowledgment of their status as a language community. This is a hardfought shift in perception, as Deaf people have hitherto been positioned by mechanisms of policy, funding and service delivery within medical and education models that define and respond to deafness in terms of auditory impairment and individualized 'special' needs. In relation to Maori social policy, Durie argues the inadequacy of a needs-based formula that centres on individuals and their socio-economic status, without acknowledging evidence of the collective socio-historical impacts of ethnicity and race on the group. ${ }^{51}$ The NZSL Act acknowledges such collective impacts on the Deaf community.

The Explanatory Note to the NZSL Bill ${ }^{52}$ contests an 'individual needs' and 'deficit' model in its definition of NZSL users as a cultural group, stating: "The capitalized "D" in "Deaf" is used internationally to denote a distinct linguistic and cultural group of people who are Deaf and who use sign language as their first or preferred language, and includes those Deaf people who identify with that group and with Deaf culture'. This change of frame around Deaf people's needs catches up with 20 years of identity politics in the Deaf world, and is also consistent with the 1992 proposal for a national languages policy which positioned the Deaf community within a language planning framework. ${ }^{53}$ Understanding deafness as a particular form of human cultural experience 'provides a way for Deaf people to re-imagine themselves as not so much adapting to the present, but inheriting the past. It allows them to think of themselves not as unfinished hearing people but as cultural and linguistic beings in a collective world with one another. ${ }^{54}$ During an era in which scientific solutions for physical imperfections dominate the public imagination (in the form of genetic engineering and prosthetic devices such as cochlear implants, for example), the cultural-linguistic perspective on Deaf people is an important counterbalance to have represented within the discourse of social policy.

In terms of instrumental rights, official status potentially lays a foundation for the administrative extension of NZSL access to education, social services and other areas that present language barriers. In Australia, the status of their sign language, Auslan, is recognized in a weaker form in government language and literacy policy statements, as a 'community language other than English' and the 'preferred language of the Deaf community'. Although the recognition itself does not ensure provision of services in Auslan, use of Auslan in Deaf education and publicly-funded provision of sign language interpreting services has reportedly increased as a result. ${ }^{55}$

The scope of the NZSL Act does not directly promise support for corpus or acquisition-planning activities, key functions of the Maori Language Commission. Public submissions and a consumer-represented working group 
on issues around the Bill both suggested a body with custodial and advisory responsibility for planning, promoting and monitoring the use of NZSL in domains that affect Deaf people's welfare. Politicians acknowledged but did not enact the idea of such a mechanism:

We discussed with submitters the prospect of establishing a New Zealand Sign Language Commission, with functions similar to the Maori Language Commission . . . We do not consider that a commission is necessary but at the same time we considered the establishment of an advisory group, which would have the role of monitoring the effects of the legislation against its stated purposes ... We consider this matter is better left to the Government to progress separately from this bill, but would recommend its serious consideration. ${ }^{56}$

This outcome reflects the political reality that support of corpus planning implies a financial and administrative burden on central government and its agencies, which would undoubtedly have impeded passage of the Bill, although in relation to a national budget it is difficult to see that this would present an untenable cost. A nod towards a 'monitoring' function is found in the guideline that government agencies should consult directly with representatives of the Deaf community on initiatives relating to their language. Anecdotal evidence suggests that the NZSL community will continue to lobby for a more formalized channel of consultation. Comparison with the recognition of Flemish Sign Language (VGT), also in 2006, highlights the New Zealand gap in provision for corpus planning. In Flanders, 'recognition entails (1) a cultural (symbolic) recognition, (2) the foundation of a commission that will advise the Flemish government in all matters related to VGT and (3) the structural funding of research and development of VGT' ${ }^{57}$ This third measure is vital to supporting the status and potential dissemination of a suppressed language. Corpus planning in the form of lexicography, analysis of the grammar and use of NZSL, and development of teaching materials has been ongoing for 20 years, mainly at the Deaf Studies Research Unit of Victoria University of Wellington, and to a lesser extent at Auckland University of Technology (the location of interpreter training) and in two Deaf Education Centres. Products of this activity have provided important documentary support for the NZSL recognition lobby, but have been somewhat constrained in scope without strategic planning or resourcing.

\section{Consideration of Educational Linguistic Rights}

Changes to the status of a sign language are rarely effected without consideration of the impact on the education of Deaf children. SkutnabbKangas argues that '(E)ducational linguistic human rights, especially the 
right to mother-tongue-medium education, are among the most important rights for any minority. Without them . . . it cannot integrate, but is forced to assimilate. ${ }^{58}$ The right to a comprehensible education in the medium of sign language is a dearly-held goal of Deaf people, because of their first-hand knowledge that 'assimilationist submersion education, where Deaf students are taught orally only, and sign languages have no place in the curriculum, often causes mental harm, including serious prevention or delay of cognitive growth potential'. ${ }^{59}$

With respect to educational linguistic rights, the NZSL Act effectively does little to strengthen the 'promotion-oriented' kind of rights often associated with language planning for education of linguistic minorities. ${ }^{60}$ This contrasts with sign language recognition measures in other countries in which education is the central site of implementation measures. Swedish Sign Language, for example, was legally recognized in 1981 specifically to mandate the provision of bilingual education for Deaf children, including support for their families to learn sign language from the time of diagnosis. Although this has not completely resolved educational under-achievement, the principles of the Swedish system are regarded as a strong educational linguistic rights model which recognizes Deaf citizens as a linguistic minority for whom bilingualism is both a legitimate social status but also an educational right. ${ }^{61}$ Norway, Finland and Uganda are among other nations that have recognized sign language as a rightful first language of Deaf children and provide substantial government resources for parent and child education in sign language from an early age.

Language planning also occurs non-legislatively, especially in the education, health and justice sectors, where the rights of language minorities may receive special protection in policy and practice. ${ }^{62}$ In the New Zealand education sector, some evidence of status and implementation planning for NZSL is found in the policy statement, National Plan for Education of Deaf and Hearing Impaired Children which 'supports the use of NZSL and written and spoken English' for Deaf learners, and recognizes the Deaf community as 'a natural community of interest and as a cultural resource in relation to Deaf and hearing impaired children'. ${ }^{63}$ Recognition of NZSL in this policy was achieved by 'bottom-up' advocacy, rather than by topdown, governmental initiative.

Consistent with the spirit of, though not originating in, the NZSL Act, the Ministry of Education has recently released the document New Zealand Sign Language in the New Zealand Curriculum which 'positions NZSL as a language of choice alongside other languages offered in mainstream schooling, that is, as a language that can be learned by hearing students'. ${ }^{64}$ Development of the human and material resources that will be necessary 
for schools to utilize this curriculum remains to be addressed, with a real risk that delivery of this curriculum will not be in the hands of Deaf NZSL users.

In general, Deaf children's need for education through sign language is treated as a discretionary matter according to individual needs determined by parents, a professional verification (of needs) process and Individual Education Plans, rather than on the basis of a collective language right associated with being Deaf. Children's access to NZSL is ultimately determined at the level of the school, specialist education advice and available resourcing. Research on the communication conditions for Deaf children in mainstream schools and lobbying by parent groups indicates that the effectiveness of an 'individual needs' approach to NZSL acquisition is inconsistent and generally inadequate..$^{65}$

Aspirations for educational linguistic rights, a core concern of the Deaf community, are sidestepped in the Select Committee report, which stated that,

Many [submitters] recommended provision be made for the use of New Zealand Sign Language in education. While we are sympathetic to submitters' concerns, we note that interdepartmental working groups are working towards the development of long-term plans for the removal of language barriers for the Deaf community in four priority areas: health, education, employment, and public broadcasting. ${ }^{66}$

'Removal of language barriers' is a weaker and less measurable proposition than the establishment of a right or an obligation; moreover, the import of language policy in the education system is qualitatively different than in areas such as employment or broadcasting. Collapsing these domains together and delegating them to working groups that lack implementation powers portend a long road towards change, unless robust consumer lobbying is maintained.

\section{A Pragmatic Marriage of Disability and Linguistic Human Rights}

In radical Deaf identity politics, disability and cultural-linguistic models of deafness paradigms are often presented as diametrically opposed ${ }^{67}$ although many Deaf advocates also acknowledge the political and material benefits of jointly advocating for the mutual goal of Deaf and disabled communities to achieve equality of opportunity. ${ }^{68}$ Whereas Deaf people advocate for sign language recognition within a linguistic human rights framework of cultural self-determination, the NZSL Act is actually predicated on a hybrid of disability rights claims (which focus on integrative, equity goals) and linguistic rights arguments, both of which ultimately stem from basic 
human rights. This juxtaposition of deafness as linguistic identity and as disability is explicit in the Explanatory Note of the Bill: 'This Bill will provide official recognition of NZSL as a unique New Zealand language and will contribute to achieving the vision of the New Zealand disability strategy: a fully inclusive New Zealand society'. ${ }^{6}$

MPs speaking to the Bill in Parliament generally focused on the integrative value of sign language as a route to inclusion (by communication access) and social equity. Not surprisingly, Maori MPs were most sensitive to the cultural autonomy agenda of Deaf New Zealanders, as exemplified in the speech of Tariana Turia (co-leader of the Maori Party) at the first reading of the Bill:

It is from the normalizing of Maori language as an ordinary language, as a living language, that our world changed . . . And yet for another significant population within Aotearoa, the same but different experiences of marginalization, of isolation, of prejudice will also have shaped their memories of expressing themselves in their language. We have heard the stories of Deaf children's hands being strapped behind their backs to stop them signing. The existence of sign language was for years ignored by officialdom. This new Bill confronts all those days gone by through establishing New Zealand Sign Language with the official recognition of a national language, with the purpose of giving it proper status and of giving the Deaf access to interpreters for legal proceedings. ${ }^{70}$

Maori members also particularly emphasized the potential for community advancement through language ownership - as, for example, in Pita Sharples' (co-leader of the Maori Party) statement that 'the Maori Language Act in Aotearoa provides an excellent resource to assist the Deaf community in identifying possible pathways for mobilising and monitoring your agenda'. ${ }^{71}$ Maori members, as well as others, contended that the Bill did not go far enough in creating instrumental rights to realize its purpose.

In an examination of ethnic and race-based social policies pertaining to Maori, Durie identifies three broad goals which equally capture the driving motives of the NZSL Act, as follows:

1. fairness between members of society (the equity goal);

2. full participation in society and its institutions (the participatory goal);

3. access to indigenous culture, networks and resources (the indigeneity goal). ${ }^{72}$

In the NZSL Act, equity and participatory goals draw on the Disability Strategy as a basis, while the indigeneity goal (expressed in the definition 
of Deaf people as a cultural community with a language unique to New Zealand, who should be consulted on matters affecting their language) calls on the precedent of the Maori Language Act. Weaving these two existing policies into a framework around Deaf people's language issues undoubtedly strengthened the political platform for the NZSL Act.

\section{Conclusion}

The story of the NZSL Act illustrates the intrinsically ideological nature of language policy, insofar as the status accorded to a language defines its speakers as 'insiders' or 'outsiders', and may be an instrument of domination or empowerment of that group. ${ }^{73}$ Making NZSL an official language acknowledges Deaf people's structural marginalization in New Zealand society and re-positions them as an ethno-linguistic community with an indigenous claim to linguistic protection. Ideologically, the Act responds to the Deaf community's wish for symbolic validation of their language and culture. Yet their second expressed aspiration for instrumental rights to access education and other public services through NZSL is addressed in the provisions of the Act with minimal enforceable obligations or support. Given that the use of NZSL is actually a communicative necessity rather than a social or linguistic preference for Deaf people, the limited implementation rights conferred by the Act risk falling short of realizing the ideals expressed by all parties in the discourse surrounding its creation.

Nevertheless, official language status provides ballast and direction for government agencies to consider and strategically enhance the inclusion of Deaf people in their operations. The apparent gap between aspirations and legal provisions will also likely be a catalyst for further grassroots lobbying by the NZSL community, whose understanding and expectations of the political process have been raised by the entire process.

Granting NZSL official language status signals a more linguistically and culturally diverse and inclusive conception of New Zealand as a nation. As May points out, ${ }^{74}$ broader representation of the linguistic realities of society at policy level is an important acknowledgement of the historical inequalities and social marginalization experienced by minorities (such as Deaf and Maori), and in practical terms offers the potential to improve their life chances through measures that enable access to education, employment and public services in their preferred language. Although official language status will not immediately effect change to the degree desired, recognising Deaf people's right to exercise citizenship in NZSL is an historic step towards raising the mana of their language and community. 


\section{Journal of New Zealand Studies}

\section{Appendix}

TABLE 1 - Comparison of the Maori Language Act 1987 and NZSL Act 2006 (provisions paraphrased)

\section{Maori Language Act}

s3 Maori declared to be an official language, indigenous to NZ

s4 Right to speak Maori in legal proceedings

s4(3) Presiding officer of the court must ensure that a competent interpreter is available

s5 Effect of recognition - does not affect existing rights to communicate in Maori not specified in the Act, nor the rights of any other linguistic community

\section{s6 Establishment of Maori Language} Commission, to -

a. initiate, develop, co-ordinate, review, advise upon, and assist in the implementation of policies, procedures, measures, and practices designed to give effect to the declaration in section 3 of this Act of the Maori language as an official language of New Zealand

b. promote the use of Maori language

c. assess competency in the Maori language (re. translation and interpreting)

d. to consider and report to the Minister upon any matter relating to the Maori language e. other functions as may be conferred upon the Commission by any other enactment

s14 Money to be appropriated by Parliament for purposes of this Act - All fees, salaries, allowances, and other expenditure payable or incurred under or in the administration of this Act shall be payable out of money to be appropriated by Parliament for the purpose

s15 Commission to grant certificates of competency in the Maori language:

- Qualification, certification of interpreters and translators

- Endorsement of interpreter and translator certification of competence for purposes of legal proceedings

- Monitoring and disciplinary role - complaints procedure

\section{NZSL Act}

s6 NZSL declared to be an official language, unique to $\mathrm{NZ}$

s7 Right to use NZSL in legal proceedings, where it's a person's preferred or first language

s7 (3) Presiding officer of the court must ensure that a competent interpreter is available

s8 Effects of recognition - does not affect existing rights to use NZSL, nor the rights of any other linguistic community

s9 A government department should, when exercising its functions and powers, be guided, so far as reasonably practicable, by the following principles:

- The Deaf community should be consulted on matters that affect their language (NZSL)

- NZSL should be used for the promotion of services and information

- Government information and services should be accessible to Deaf people in different ways, including New Zealand Sign Language

s10 The Minister may from time to time report on the progress being made in implementing the principles set out in section 9 (Reporting by government departments via reporting mechanism for the NZ Disability Strategy)

NA

[Effects of the NZSL Act to be reviewed after three years]

s13 Regulations: The Governor-General may make regulations which prescribe standards of competency required of NZSL interpreters in legal proceedings, and regulations which determine assessment criteria relating to standards. 
1 R. Johnson and C. Erting, 'Ethnicity and Socialization in a Classroom for Deaf Children', in Ceil Lucas, ed., The Sociolinguistics of the Deaf Community, New York, 1989; O. Sacks, Seeing Voices: A Journey into the World of the Deaf, London, 1990, p.49.

2 T. Reagan, 'Language Policy and Sign Languages', in T. K. Ricento, ed., An Introduction to Language Policy - Theory and Method, Malden, MA, 2006, pp.329-45; World Federation of the Deaf, 'Sign Language. Fact Sheet', 2006. Accessed 27 August 2006 at: http://www.wfdeaf.org/pdf/fact_signlanguage.pdf.

3 R. Fasold, The Sociolinguistics of Society. Oxford, cited in C. Ramsey, 'Language Planning in Deaf Education', in Lucas, The Sociolinguistics of the Deaf Community, p.124.

4 Reagan, 'Language Policy'.

5 V. Fromkin, 'On the Uniqueness of Language', in K. Emmorey and H. Lane, eds, The Signs of Language Revisited: An Anthology to Honor Ursula Bellugi and Edward Klima, Mahwah, NJ, 2000, pp.533-47; W. Stokoe, Sign Language Structure (Revised), Maryland, 1978; S. Fischer and P. Siple, eds, Theoretical Issues in Sign Language Research, Vol. One, Linguistics, Chicago, 1990.

6 J. Branson and D. Miller, 'Language and Identity in the Australian Deaf Community: Australian Sign Language and Language Policy - An Issue of Social Justice', Australian Review of Applied Linguistics, Series S (1991), pp.135-76; Ramsey, 'Language Planning'; D. Stewart, 'Bi-Bi to MCE?', American Annals of the Deaf, 138 (1993), pp.331-7.

7 Fishman, 1974, cited in Ramsey, 'Language Planning', p.124.

8 D. Baynton, Forbidden Signs: American Culture and the Campaign Against Sign Language, Chicago, 1996; W. Forman, 'Toward a Critique of the Exclusive Use of Oral Methods in Education of the Deaf', New Zealand Journal of Disability, 7 (2000), pp.40-56; S. Nover, 'Politics and Language; ASL and English in Deaf Education', in Lucas, The Sociolinguistics of the Deaf Community, pp.109-63; Ramsey, 'Language Planning'.

9 Reagan,'Language Policy', pp.332-3.

10 For example, H. Lane, When the Mind Hears: A History of the Deaf, New York, 1984.

11 Reagan, 'Language Policy'; Wikipedia, 'Legal Recognition of Sign Languages', 2006. Accessed 27 August 2006 at: http://en.wikipedia.org/wiki/Recognition_of_sign_ languages.

12 N. Timmermans, A Comparative Analysis of the Status of Sign Languages in Europe, Dutch Ministry of Health, Welfare and Sport, Strasbourg, 2003, p.3.

13 World Federation of the Deaf, 'Sign Language. Fact Sheet'.

14 M. Jokinen, 'The Linguistic Human Rights of Sign Language Users', in Robert Phillipson, ed., Rights to Language: Equality, Power, and Education: Celebrating the 60th Birthday of Tove Skutnabb-Kangas, Mahwah, NJ, 2000, pp.203-13; L. Siegel, 'The Argument for a Constitutional Right to Communication and Language', Sign Language Studies, 6 (2006), pp.255-72.

15 See Jokinen, 'The Linguistic Human Rights'; T. Skutnabb-Kangas, 'Linguistic Human Rights: A Prerequisite for Bilingualism', in I. Ahlgren and Kenneth Hyltenstam, eds, Bilingualism in Deaf Education, Hamburg, 1994, pp.139-59.

16 C. Padden and T. Humphries, Deaf in America: Voices from a Culture, Cambridge, Mass., 1988. 


\section{Journal of New Zealand Studies}

17 T. Johnston, 'W(h)ither the Deaf Community? Population, Genetics, and the Future of Australian Sign Language', American Annals of the Deaf, 148 (2004), pp.358-75.

18 Ramsey, 'Language Planning', p.127.

19 R. McKee, People of the Eye: Stories from the Deaf World, Wellington, 2001; Padden and Humphries, Deaf in America.

20 H. Lane, The Mask of Benevolence: Disabling the Deaf Community, New York, 1992; Padden and Humphries, Deaf in America.

21 P. Ladd, Understanding Deaf Culture. In Search of Deafhood, Clevedon, 2003; Lane, When the Mind Hears; Lane, The Mask of Benevolence; McKee, People of the Eye; D. Moskovitz and A. Walton, 'New Zealand Sign Language and Deaf Mana', Unpublished Paper presented at the National Community Languages and TESOL Conference, Wellington, 1990; S. Townsend, "The Hands Just Have to Move": Deaf Education in New Zealand - A Perspective from the Deaf Community', MA Thesis, Massey University, 1993; O. Wrigley, The Politics of Deafness, Washington DC, 1996.

22 T. Johnston, 'BSL, Auslan and NZSL: Three Signed Languages or One?', Paper presented to the 7th International Conference on Theoretical Issues in Sign Language Research (TISLR), Amsterdam, July 2000; D. McKee and G. Kennedy, 'A Lexical Comparison of Signs in Australian Sign Language, British Sign Language, and New Zealand Sign Language', Proceedings of the 1st Australasian Deaf Studies Symposium, Sydney, 2000.

23 Forman, 'Toward a Critique'; L. Monaghan, 'Signing, Oralism and the Development of the New Zealand Deaf Community: An Ethnology and History of Language Ideologies', Anthropology PhD, University of California, 1996; Townsend, “"The Hands Just Have to Move",

24 P. Ballingall, 'The Sign Language of Deaf Children in New Zealand', MA thesis, University of Auckland, 1972.

25 M. Collins-Ahlgren, New Zealand Sign Language and the Aim of Total Communication for the Deaf, SET, Wellington, 1986.

26 M. Collins-Ahlgren, 'Aspects of New Zealand Sign Language', PhD thesis, Victoria University of Wellington, 1989.

27 The original three-month training course for sign language interpreters in 1985 was an initiative of the NZ Deaf Association, funded by the Department of Social Welfare and the Roy McKenzie Education Foundation. An interpreter educator, Dan Levitt, from California State University Northridge was contracted to teach the course of eight trainees. Levitt was a fortunate choice in that he was proactive in involving the local Deaf community in the training (of necessity, since no NZSL materials were available for teaching purposes), and also carefully documenting their language as he went. Their involvement in this 'action research' inspired a palpable shift in Deaf people's attitude towards their own language and capabilities. The author is a graduate of that course.

28 D. Levitt, Introduction to New Zealand Sign Language, Auckland, 1986.

29 P. Dugdale, Talking Hands, Listening Eyes: The History of the Deaf Association of New Zealand, Auckland, 2000; H. McCormack, 'Between Two Worlds - Breaking the Sound Barrier' (Interviewed and edited by Peter Beatson), New Zealand Journal of Disability Studies, 8 (2001), pp.3-35.

30 R. McKee, 'Interpreting as a Tool for Empowerment of the New Zealand Deaf Community', in S. Fenton, ed., For Better or Worse. Translation as a Tool in the South Pacific, Manchester, 2003. 


\section{The Eyes Have It! Our Third Official Language}

31 P. Dugdale, 'Being Deaf in New Zealand. A Case Study of the Wellington Deaf Community', PhD thesis, Victoria University of Wellington, 2000; Statistics New Zealand, 'New Zealand Disability Survey Snapshot 6: Sensory Disabilities', Wellington, 2001.

32 A. Wolf, The New Zealand Sign Language Bill (Case Program), Parkville, Victoria, 2005 .

33 Ibid.

34 Minister for Disability Issues, The New Zealand Disability Strategy, 2001. Accessed 1 September 2006 at: http://www.odi.govt.nz/publications/nzds/index.html.

35 Wolf, The NZSL Bill.

36 Office for Disability Issues, History - New Zealand Sign Language Bill, 2006. Accessed 28 August 2006 at: http://www.odi.govt.nz/what-we-do/nzsl-history.html.

37 Wolf, The NZSL Bill, p.3.

38 Office for Disability Issues, History.

39 This summary is based on my examination of written submissions made publicly available by the Secretary to the Justice and Electoral Select Committee, Parliament, and my observations at the oral submissions held in Wellington, 9 February 2005.

40 A. Fraser and V. Sim, Legal Advice: Consistency With The New Zealand Sign Language Bill of Rights Act 1990: New Zealand Sign Language Bill, ed. Public Law Group, Ministry of Justice, Wellington, 2003.

41 Explanatory Note, NZSL Bill 2004, p.1.

42 D. Knight, 'Linguistic Discrimination in Education: The Minority Language Speaker's Right to Meaningful Education', Human Rights Law and Practice, 2 (1996), pp.75-94; C. Lane, 'Language and New Zealand Human Rights Law', Paper presented at Language and Society Conference, 12 August 1998, University of Auckland.

43 C. Lane, K. Mackenzie-Bridle and L. Curtis, 'The Right to Interpreting and Translation Services in New Zealand Courts', Forensic Linguistics, 6 (1999), pp.111-31.

44 M. Durie, 'Race and Ethnicity in Public Policy: Does it Work?', Social Policy Journal of New Zealand, 24 (2005), pp.1-11.

45 NZSL Bill 2004, p.1.

46 MLA s14.

47 Justice and Electoral Select Committee, New Zealand Sign Language Bill, as reported from the Justice and Electoral Committee, House of Representatives, Wellington, 2005, p.5.

48 N. Hornberger, ' Frameworks and Models in Language Policy and Planning', in Ricento, An Introduction to Language Policy, pp.24-41.

49 Ibid., p.32.

50 S. May, 'Language Policy and Minority Rights', in Ricento, An Introduction to Language Policy, pp.255-72.

51 Durie, 'Race and Ethnicity in Public Policy: Does it Work?'.

52 NZSL Bill 2004, p.1.

53 J. Waite, Aoteareo: Speaking for Ourselves - Part B: The Issues, Wellington, 1992.

54 C. Padden and T. Humphries, Inside Deaf Culture, Harvard University Press, 2005, p.161.

55 Wikipedia, 'Legal Recognition of Sign Languages'. 


\section{Journal of New Zealand Studies}

56 Justice and Electoral Select Committee, New Zealand Sign Language Bill, p.5.

57 Wikipedia, 'Legal Recognition of Sign Languages'.

58 T. Skutnabb-Kangas, 'Language Policy and Linguistic Human Rights', in Ricento, An Introduction to Language Policy, p. 275.

59 Ibid., p.279.

60 S. May, Language and Minority Rights: Ethnicity, Nationalism and the Politics of Language, Language in Social Life Series, Essex, 2001.

61 S. Bagga-gupta and Lars-Ake Domfors, 'Pedagogical Issues in Swedish Deaf Education', in L. Monaghan, C. Schmaling, K. Nakamura and G. Turner, eds, Many Ways to be Deaf: International Variation in Deaf Communities, Washington DC, 2002, pp.67-88.

62 Reagan, 'Language Policy and Sign Languages'; May, Language and Minority Rights.

63 Deaf Education Aotearoa New Zealand, National Plan for the Education of Deaf and Hearing Impaired Children and Young People in Aotearoa/New Zealand, 2005, p.21.

64 Ministry of Education, online edition of New Zealand Sign Language in the New Zealand Curriculum, 2006. Accessed 24 March 2007, at: http://www.tki.org.nz/r/language/ curriculum/nzsl/index_e.php.

65 P. Laing, 'Migrating Towards a Deaf World: An Experience of a Hearing Parent of a Deaf Child', DEANZ (Deaf Education Aotearoa-New Zealand) Journal (2004); R. McKee, 'As One Deaf Person to Another: Deaf Paraprofessionals in Mainstream Schools', Deaf Worlds, 21 (2005), pp.1-48; R. McKee, 'Connecting Hearing Parents with the Deaf World', Sites (New Series), 3 (2006); R. McKee and E. Smith, Report on a Survey of Itinerant Teachers of the Deaf with 'High' and 'Very High Needs' Deaf Students in Mainstream Schools, Deaf Studies Research Unit, Research Report No. 2, Victoria University of Wellington, 2003, available at http://www.vuw.ac.nz/lals/research/deafstudies/DSRU; R. McKee and E. Smith, Report on a Survey of Parents of 'High' and 'Very High Needs' Deaf Students in Mainstream Schools, Deaf Studies Research Unit, Research Report, No. 1, Victoria University of Wellington, 2003, available at http://www.vuw.ac.nz/lals/ research/deafstudies/DSRU; Dominion Post (Wellington), 'Good Signs', 13 March 2006, p.A4.

66 Justice and Electoral Select Committee, New Zealand Sign Language Bill, pp.5-6.

67 See Lane, The Mask of Benevolence, for an exposition of this position.

68 S. Robinson and R. Adam, 'Cultures of Disability and Deafness: Rethinking the Links Between the Disability Movement and the Deaf Community', Paper presented at The Australian Social Policy Conference, University of NSW, July 2003.

69 NZSL Bill Explanatory Note, p.2.

70 Hansard, Second Reading of the New Zealand Sign Language Bill, 23 February 2006. Accessed 1 September 2006, at: http://www.hansard.parliament.govt.nz/hansard/Final/ FINAL_2006_02_23.htm\#_Toc129585410.

71 Ibid.

72 Durie, 'Race and Ethnicity in Public Policy'.

73 J. Tollefson, Planning Language, Planning Inequality: Language Policy in the Community, London, 1991, cited in Reagan, 'Language Policy and Sign Languages', p.339.

74 May, 'Language Policy and Minority Rights', p.267. 